\title{
THE INFLUENCE OF DISSIMILARITY OF COMPARABLES ON THE CORRECTNESS OF ESTIMATION IN THE COMPARATIVE APPROACH PROCEDURE
}

\author{
Jacek Zyga \\ Faculty of Engineering and Architecture \\ Lublin University of Technology \\ e-mail:j.zyga@pollub.pl
}

Abstract

The subject of this article is the still relevant issue of the adequate choice of comparables in evaluation procedures within the sales comparison approach. The text features the results of an experiment that makes it possible to validate the dependence of the accuracy of the final estimation of the price of valued objects in relation to the criteria of significance of similarity as a determinant of accepting individual objects as sufficiently similar, and the dissimilarity coefficients describing the created reference sets. Based on the example of simulated data, it has been shown that there is a clear relationship between the accuracy of the estimates made and the selection of comparables. In a set of all possible calculation variations, estimations based on selected data are characterized by more accurate calculations relative to parallel calculations carried out on the widest possible sets of comparables.

Key words: dissimilarity, property price model, comparables selection, property valuation.

JEL Classification: $R 15$, C18, C38, C51.

Citation: Zyga, J. (2021). The influence of dissimilarity of comparables on the correctness of estimation in the comparative approach procedure. Real Estate Management and Valuation, 29(1), 12-20.

DOI: https://doi.org/10.2478/remav-2021-0002

\section{Introduction}

The sales comparison approach in real estate valuation came into existence thanks to the practice and observation of simple market relations. Therefore, simplicity should be sought in the search for better estimation methods. Meanwhile, in the end of the twentieth and beginning of the twenty-first century, complicated procedures and complex valuation systems became a trend. Along with the development of theoretical opportunities offered by mathematics (or more accurately, mathematical statistics), and the arming / providing real estate analysts with better computational tools, both academics and valuation practitioners are focusing more and more attention on the automation of the valuation process and the possibilities of analysing increasingly larger data sets ( $\mathrm{D}^{\prime}$ Amato, Kauko, 2017). As rightly noted by M. Ciuna, M. Ruggiero, F. Salvo and M. Simonotti (Ciuna, et al., 2017), valuation based on regression models is difficult to apply in some real estate markets, so an attempt was made to check whether it is possible to tailor typical regression methods to local conditions, determined by real estate sets, which are most similar to the subject of valuation in a widely understood market.

In the following article, an attempt was made to assess the estimation of the subject based on fewer selected data sets and to compare the accuracy of such estimation with the veracity of estimations that use more extensive data sets. The essence of the difference between the proposed algorithm and the typical multiple regression is the proposition to limit the initial / input data set to the prices of similar comparables only. 


\section{Review of literature}

Valuation procedures have evolved along with the development of the economy and the methods and possibilities of describing it. The development of the market economy and recorded real estate transactions gave rise to the sale comparison approach (Anderson, 1960; Shenkel \& Eidson, 1971). Technological progress in the field of data collection and processing has enabled the introduction, decade by decade, of newer valuation concepts. The number of examples of such attempts is huge, making it difficult to list them all. One of the most important summaries is the work (Colwell, et al., 1983) describing, in addition to the principles and possibilities of a comparative approach in real estate valuation, the possibilities of effective use of the least squares method. Diaz (1990) evaluates these possibilities rather critically, pointing to the neglected issue of data selection. Studies summarizing the periodic state of the art of the comparative approach may also include: Tchira (1979), Peto et al. (1996), Pagourtzi et al. (2003), Moore (2009) or McCluskey and Borst (2017). Interestingly, Tchira (1979), in the second half of the twentieth century, and McCluskey and Borst (2017) in the second decade of the twenty-first century, share Diaz's observations of some neglect of data selection and highlight its role in the valuation process implemented in a comparative approach. The remaining publications treat the issue of selecting data for valuation as a more technical element and see it as an econometric point of view. Peto, French and Bowman (1996) explain the valuation philosophy and the process of gradual changes in its technology over time. At the same time, they point to the difference between the concepts of 'price' and 'value'. These concepts, already discussed by Albritton (1982), are not often distinguished, despite current directives from different professional standards in the field of real estate valuation (SCPFVA 2009, IVSC 2010, RICS 2017, USPAP 2017). Similar is true when it comes to the distinction between the concepts of "estimate of value" and "opinion of value". While combining estimation terms with market value was widely accepted in the eighties and nineties of the last century (Albritton, 1982), nowadays "estimate of value"' is being merged with the automated value determination process (d'Amato \& Kauko, 2017; Glumac \& Des Rosiers, 2018), leading to sums which are described as "appraisal value", whereas the individual "opinion of value" is expressed by the socalled "assessed value" (Ciuna, et al., 2015), seen as synonymous with market value.

Simple pairwise comparison and the associated transaction selection have always been the basis for a comparative approach. However, these issues were largely underestimated by "business other than real estate appraisal" (Diaz, 1990). Due to the fact that many other sectors of the economy are interested in the real estate industry, the strictly workshop-wise issue of data selection disappeared gradually in the flood of quantitative methods. Simplified valuation methods were relatively quickly supplemented or even replaced by computer support techniques based on multiple regression methods, e.g. CAA - Computer Assisted Assessments (Shenkel, 1970), CAMA: computer-assisted mass appraisal (Dilmore, 1974; Tchira, 1979). In this way, heuristic abilities constituting the essence of the valuer profession were replaced by automated inference. The first scientific attempts to apply quantitative methods (mainly hedonic methods) took place as soon as in the middle of the last century (Moore 2009). These methods primarily used ordinary least squares (OLS) procedures and linear or nonlinear models. Over the next decades, a lot of modifications were made to their basic versions by diverse statistical techniques, such as multilevel models (Simonotti, et al., 2014; Arribas, et al., 2016), robust regression (Janssen, et al., 2001) or autoregressive models (Bourassa, et al., 2010, 2013; Del Giudice, et al., 2017). Neural networks were also involved in valuation (Kontrimas \& Verikas, 2011; Chun Lin \& Mohan, 2011; Mimis, et al., 2013) and fuzzy logic (González \& Formoso, 2006; Lughofer, et al., 2011; Wang, et al., 2015). The heuristic abilities of the listed groups of methods work best in analysing entire markets (Trojanek, 2010; Kozioł-Kaczorek, 2012; Brzezicka \& Wiśniewski 2012; Simonotti, et al., 2014; Bracke, 2015; Dmytrów \& Gnat, 2019), examining their regularity or disturbances, finding traces of economic events (Shiller, 1990; Żelazowski, 2008) and studying the spatial distribution of phenomena (Bittner, et al., 2007; Celmer, 2014; Bourassa et al. 2007, 2010), trends or threats (Bianco, 2008; Bełej, 2013). Some of the few attempts to develop statistical methods in the field described today as giving opinions on value were: the Isakson concept aimed at simplification through a simple selection of the closest comparables, classified by the author as "the Nearest Neighbours Appraisal" (Isakson, 1986) and some contemporary research of Barańska (2016) focused on the influence of database size on predicting the property market value. 


\section{Methodology}

The essence of the comparative approach has always been proper market knowledge, manifested in the knowledge of price forming processes. These processes are often typical. Systems of factors significant in one market can, therefore, be transferred and used in other markets. However, it is not uncommon for special factors to appear in price formation, which should be recognized and taken into account. Sometimes the uniqueness of certain subsets of transactions is simply manifested in the fact that the real estate properties they cover are very similar to each other and, at the same time, to the subject of the valuation. In these situations, it is justified to drop the analysis of sale cases as a whole in favor of the analysis of the selected few. This process approximates the "estimate of value" procedure to the essentially simplified "opinion value". This, in turn, allows you to equate the result of accounting activities with market value [market value / assessed value].

In the analysis of sets covering all available transactions and related information about the subjects of these transactions, using the general regression model, the above-mentioned specific conditions of small subsets of prices can be ignored and treated as information noise. This may mean losing the information potential contained in the omitted specific qualities of selected elements. However, an analogical value analysis based only on selected transactions can give more accurate results.

The analysis presented below uses the typical least squares method in the general linear multiple regression model:

$$
Y_{A}=A X_{A}+\varepsilon_{A}
$$

where:

$Y_{A} \quad$ - price vector of all sales; $n_{A}$ rows,

$X_{A} \quad$ - vector of model parameters; $k_{A}$ rows,

$A \quad$ matrix $\left(n_{A} \times k_{A}\right)$ of all possible values of attributes (market features) built on the set of all sales

$\varepsilon_{A} \quad$ - vector of stochastic components

with a typical formula for predicting values for an item outside the reference set

$$
\widehat{Y_{F A}}=F_{A}\left(A^{T} A\right)^{-1} A^{T} Y_{A}
$$

where:

$\widehat{Y_{F A}} \quad$ - value prediction of the appraised item/object factored out of the reference set

$F_{A} \quad$ - vector of attributes (market features) of the subject property, corresponding with the dimension of $X_{A}$

The "FA" index indicates the relationship between the prediction result $\widehat{F_{F A}}$ and the unique characteristics of the valuation object included in the vector $F_{A}$ and the set of market information $\left(Y_{A}, A\right)$.

Parallel to simply solving the task of estimating the value of subsequent valuation subjects, the "sales" selection procedure is carried out in terms of their similarity to subsequent valuation subjects and re-estimation of their value based on selected "sales".

$$
\begin{aligned}
& Y_{B}=B X_{B}+\varepsilon_{B}, \\
& \widehat{Y_{F B}}=F_{B}\left(B^{\mathrm{T}} B\right)^{-1} B^{\mathrm{T}} Y_{B},
\end{aligned}
$$

where:

$Y_{B} \quad$ - price vector of selected comparables,

$X_{B} \quad$ - vector of attributes (market features),

$B \quad$ - matrix $\left(n_{B} \times k_{B}\right)$ of all possible values of attributes (market features) built on the set of selected sales; $n_{B}<n_{A}$,

$\varepsilon_{B} \quad$ - vector of stochastic components,

$\widehat{Y_{F B}} \quad$ - value prediction of the appraised item/object taken from outside the reference set based on the set of selected sales,

$F_{B} \quad$ - vector of attributes (market features) of subject property, corresponding with the dimension of $X_{B}$.

The estimates $\widehat{Y_{F A}}$ and $\widehat{Y_{F B}}$ in principle, are different and different from the corresponding true value $Y_{T}$ which comes directly from $Y_{T}=F_{A} X_{A}$. The "true" values, which are not affected by random errors $\varepsilon_{A}$ like in (1), are joined to all corresponding "real" prices $Y_{A}$ or $Y_{B}$, simulated in the experiment. 
The difference in relation to this value is an indicator of the accuracy of each estimate.

$$
\begin{aligned}
& \widehat{Y_{F A}}-Y_{T}, \\
& \widehat{Y_{F B}}-Y_{T},
\end{aligned}
$$

The degree of mutual similarity, or rather dissimilarity between comparables and the set valuation subject, is a widely agreed upon factor that determines the selection of comparables. As a measure of dissimilarity of comparables at the stage of selection is the difference: $d_{A i, j}$ (Zyga, 2019):

$$
d_{A i, j}=a_{i, j}-f_{1, j}
$$

Where:

$a_{\mathrm{i}, \mathrm{j}} \quad$ - is the $\mathrm{i}, \mathrm{j}$ element of matrix $A, \mathrm{i} \in\left\langle 1, n_{A}\right\rangle$ where $n_{A}$ is also a number of observations in $Y_{A}, j \in$ $\left\langle 1, k_{A}\right\rangle$ where $k_{A}$ is also a number of structural parameters $X_{A}$,

$f_{1, \mathrm{j}} \quad$ - is the jelement of the single-line matrix of the $F_{A}$ pattern, $j \in\left\langle 1, k_{A}\right\rangle$

Comparing the valuation subject to the full set of attributes A leads to the construction of the matrix:

$$
D_{A}=A-[1] F_{A}
$$

With dimensions analogous to the matrix $A$ i.e. $\left(n_{A} \times k_{A}\right)$. On the basis of matrix $D_{A}$ a coefficient is then constructed DissA expressing the level of dissimilarity of the selected valuation subject with respect to all comparables described in $\mathrm{A}$ :

$$
\operatorname{Diss} \mathrm{A}=\frac{\sum_{\mathrm{i}=1}^{\mathrm{n}_{\mathrm{A}}} \sum_{\mathrm{j}=1}^{\mathrm{k}_{\mathrm{A}}}\left(D_{\mathrm{A}_{\mathrm{i}, \mathrm{j}}}\right)^{2}}{\mathrm{n}_{\mathrm{A}}},
$$

An analogous DissB coefficient can be constructed for each B matrix, built as a result of selecting a subset of real estate properties most similar to the object of the valuation.

$$
d_{B i, j}=b_{i, j}-f_{1, j}
$$

where:

$b_{\mathrm{i}, \mathrm{j}} \quad$ - is the $\mathrm{i}, \mathrm{j}$ element of matrix $B, \mathrm{i} \in\left\langle 1, n_{B}\right\rangle$ where $n_{B}$ is also a number of observations in $Y_{B}, j \in$ $\left\langle 1, k_{B}\right\rangle$ where $k_{B}$ corresponds with a number of structural parameters $x_{\mathrm{B}}$

$f_{1, \mathrm{j}} \quad$ - is the $\mathrm{j}$ element of the single-line matrix of the $F_{B}$ pattern, $j \in\left\langle 1, k_{B}\right\rangle$

$$
\begin{gathered}
D_{B}=B-[1] F_{B}, \\
\operatorname{DissB}=\frac{\sum_{\mathrm{i}=1}^{\mathrm{n}_{\mathrm{B}}} \sum_{\mathrm{j}=1}^{\mathrm{k}_{\mathrm{B}}}\left(D_{\mathrm{B}_{\mathrm{i}, \mathrm{j}}}\right)^{2}}{\mathrm{n}_{\mathrm{B}}},
\end{gathered}
$$

It should be noted that, as a rule, the number of columns in the matrix $A$ and $B$, respectively $k_{A}$ and $k_{B}$ may be different. This may result from the need to eliminate columns of matrix $B$, whose elements, as a result of selection, show no variability or are too weakly correlated with elements of the vector $Y_{B}$ (no significance of selected variables in the set $X_{A}$ )

In order to build a set of transactions $\left(\mathrm{Y}_{B}, B\right)$ covering real estate most similar to the subject of valuation/subject property, individual matrix elements are analyzed $D_{A \mathrm{i}, \mathrm{j}}$ and compiled into the assumed criterion value $\operatorname{dmax}_{\mathbf{j}}$ defining the accepted inconsistency of the $i$-th comparative property within the j-th quality.

$$
\begin{gathered}
D_{A \mathrm{i}, \mathrm{j}} \leq \operatorname{dmax}_{\mathrm{j}}, \\
\operatorname{dmax}_{\mathrm{j}}=\operatorname{Kmax}\left(\max _{\mathrm{i}} A_{i, j}-\min _{\mathrm{i}} A_{i, j}\right),
\end{gathered}
$$

$\mathrm{i} \in\left\langle 1, \mathrm{n}_{\text {initial }}\right\rangle$ where $\mathrm{n}_{\text {initial }}$ is a number of initially collected observations $\mathrm{y}_{\mathrm{A}}$

$\mathrm{j} \in\left\langle 1, \mathrm{k}_{\text {initial }}\right\rangle$ where $\mathrm{k}_{\text {initial }}$ is a number of initially defined structural parameters $\mathrm{x}_{\mathrm{A}}$ $K \max \in\langle 0,1\rangle$ is a declared maximum limit of accepted dissimilarity rate.

Compliance with condition (12) allows the i-th transaction price $Y_{A}$ to be included in the vector $Y_{B}$ and the corresponding row of matrix $A$ to matrix $B$. 
In order to assess the significance of individual independent variables, represented by the respective columns of the matrix $A^{\langle\mathrm{j}\rangle}$ and after selection by the columns of the matrix $B^{\langle\mathrm{j}\rangle}$, the correlation of vectors $A^{\langle j\rangle}, B^{\langle j\rangle}$ is analyzed, with the vectors of price observation, respectively $Y_{A}$ i $Y_{B}$.

$$
\begin{aligned}
& \mathrm{r}_{Y_{A}, A_{j}}=\frac{\operatorname{cov}\left(Y_{A^{A}} A^{\langle j\rangle}\right)}{\sigma_{\mathrm{Y}_{A}} \sigma_{A^{(j)}}} \geq K_{-} \text {korelmin } \\
& \mathrm{r}_{Y_{B}, B_{j}}=\frac{\operatorname{cov}\left(Y_{B}, B^{\langle j\rangle}\right)}{\sigma_{Y_{B} \sigma_{B}(j)}} \geq K_{-} \text {korelmin }
\end{aligned}
$$

where:

$\operatorname{cov}\left(Y_{A}, A^{\langle j\rangle}\right), \operatorname{cov}\left(Y_{B}, B^{\langle j\rangle}\right) \quad$ - is a covariance between indicated variables

$\sigma_{-}$

- is a standard deviation operator of selected variable

The indicator K_korelmin is a declared minimum limit of accepted correlation. Technically $K_{-}$korelmin $\in(0,1\rangle$ but for practical use it should be $K_{-}$korelmin $\in\langle 0.1,0.6\rangle$.

Not meeting the condition (15) by the selected column of the matrix $B^{\langle j\rangle}$ leads to its reduction, which may be the reason that the number of columns in matrix $A$ and $B$, respectively, $\mathrm{k}_{\mathrm{A}}$ and $\mathrm{k}_{\mathrm{B}}$ are different.

\section{Experiment}

In order to illustrate the problem, a set of simulated price observations was prepared (Zyga 2020). It is a simulated, possible picture of a small real estate market (e.g. flats or plots of land). It is composed of 102 simulated prices, calculated on the basis of five assumed parameters $X_{A}$ (assumed values of $\left.X_{A}{ }^{T}=\left(\begin{array}{lllll}100 & 80 & 30 & 20 & 10\end{array}\right)\right)$ and assigned to individual subjects assessments of their simulated features $a_{i, j}$ enclosed in a matrix in blocks $A$. From the complete set of combinations of feature valuations $a_{i, j}$ consisting of $625=5^{4}$ combinations ( 4 features described by marks from 1 to 5$), 104$ prices (1/6 of the set) and vectors of the assigned ratings were randomly selected. Then, items and extreme prices were eliminated from the selection.

Real estate attributes are usually qualitative variables (measured on an ordinal scale). In the simulated experiment, however, it was assumed that the numerically expressed ratings correspond to the measurements of selected attributes taken from the interval scale.

Each simulated property was priced as $Y_{A}=A X_{A}$ and biased with $\varepsilon_{A}(1)$. Errors $\varepsilon_{A}$ were specified randomly as:

$$
\varepsilon_{A i}=E R_{i} \cdot A X_{A}
$$

with an assumed margin of standard deviation: $\mathrm{E}(E R) 0.000$, stdev $(E R)=0.200$, $\max (E R)=0.593$, $\min (E R)=-0.620$. This simulated market was demonstrated earlier in (Zyga, 2020).

The quantities $Y_{T}=A X_{A}$ were assumed to be true, undistorted values of individual simulated transaction items, while the amounts affected by random errors $\varepsilon_{A}(1)$ were treated as real transaction prices.

Each of the simulated objects described by the attribute values contained in the respective rows of the matrix $A$, was also a potential valuation subject: $F_{A}=\left(A^{T}\right)^{\langle i\rangle}$. Estimation of its value was carried out repeatedly using subsequent variants of subsets with a controlled size of the DissA coefficient (or DissB respectively) expressing the level of dissimilarity of the selected valuation subject with comparables contained in subsequent reference sets.

A total of 16014 estimation tests were carried out. Each of the 102 valuation subjects was estimated 157 times, in different variants imposed by the acceptance criteria for the maximum dissimilarity of the properties of the comparative set: Kmax (13) and the minimum correlation of independent variables (attribute values) to prices: K_korelmin (14), (15).

Table 1 and Fig. 1 present the aggregate results of the accuracy of the estimates, more widely discussed in (Zyga, 2020). The factor called "total, relative assessment of accuracy" (TRA) presented in Fig. 1 is the sum of the accuracy indicators $\widehat{Y_{F B}}-Y_{T}(5 \mathrm{~b})$ achieved for all 102 potential valuation items in all possible options for the selection of similar properties but with a specific set of criteria regarding the acceptance of maximum dissimilarity $K \max (13)$ and minimum correlation of independent variables $K_{-}$korelmin (14), (15)

In an analogous manner, in Table 2 and Fig. 2, the averaged measures of dissimilarity DissB built on the basis (11) are presented, describing the sets of so-called similar properties that were created for 
the purposes of individual estimation attempts. The numbers presented in Table 2 and Fig. 2 are averaged DissB values produced in all possible tests performed with a given configuration of similar real estate selection factors (Kmax) and attributes (K_korelmin).

The absolute values of the DissB coefficients are irrelevant in the interpretation of the results because they may be different for each A set and the values of the feature ratings adopted in it. The proportions of the obtained results and the relations of DissB values with the coefficients for the selection of similar properties (Kmax) and attributes (K_korelmin) shown in Fig. 2 are important. Both, the combined analysis of trends shown in Fig. 1 and 2 as well as numerical analyses, show the existence of a correlation between the accuracy of estimates of test objects and the degree of dissimilarity of DissB reference sets of individual studies. However, these correlations look different in different observation groups. By comparing the relevant rows of Table 1 and 2 with each other, it becomes clear that, in cases where $\operatorname{Kmax} \in\langle 0.25,0.70\rangle$, the observable variabilities of the relative assessment of accuracy of TRA estimates of DissB dissimilarity are very concurrent. However, for $K \max \in\langle 0.75,1.00\rangle$, the above quantities are negatively correlated. The behavior of the TRA and DissB parameters in the first correlation group confirms the thesis that the more similar transaction items are used in the construction of the price model, the more accurate the estimation results (in terms of difference $\widehat{Y_{F B}}-Y_{T}(5 \mathrm{~b})$ ).

For each of the 102 analyzed simulated objects, all possible combinations of valuation were analyzed in diverse variants of selection of comparables. For a certain group of objects (approx. 59\% of cases) it was clearly observed that the increase in the DissB coefficient of the dissimilarity of comparative properties in the selected reference sets is accompanied by an increase in the value of the difference $\widehat{Y_{F B}}-Y_{T}$, which means a decrease in the accuracy of subsequent estimates. An example of this type of relation is presented in the chart (Fig.3).

In the conducted experiment, data selection was not always a favorable solution from the accuracy standpoint of the estimates made. In the set of cases in which the DissB coefficient, i.e. the coefficient of dissimilarity of the set of selected elements exceeded the coefficient (DissA $=15.74$ ) calculated for the set of all available transactions (sales), the number of cases of positive correlation of the DissB factor (11) with the accuracy of estimates $\widehat{Y_{F B}}-Y_{T}(5 \mathrm{~b})$ decreases dramatically (18.8\%-31.6\% of cases). The estimates of various subject properties using reference sets with a relatively low DissB (DissB <5), on the other hand, gave more accurate results in more than half of the cases (50.5\% of cases). This is illustrated in Table 3.

\section{Conclusions}

According to the LS theory, delimitation of the size of transaction sets, both in the number of market observations (real estate prices) and in the number of variables (features describing the objects of the transaction) formally reduces the diagnostic capabilities of the constructed system.

This is why there is a frequent effort in mass pricing and related research to use large or very large sets of transactional data. These sets are then combined with sets of characteristics based on equally numerous lists of attributes. In total, huge observation systems (dependent and independent variables) with extremely different values are therefore developed. In mass valuations, the almost principle, derived from econometric experiences, is not the elimination of price observations, but the elimination of uncorrelated characteristics attributed to the sold items. This is justified, in a certain way, because a good conditioning of model equations requires a full spectrum of dependent variable values.

The studies presented above show that there is a possibility of taking different actions. Its principle is to select price observations with a similarity (or lack thereof) to the property accepted for valuation. The studies presented above show that there is a possibility of different action. Its principle is to select the price observations based on the similarity of the sold items to the property accepted for valuation. This usually means a radical reduction in the price set and in the characteristics set of the sold items, while maintaining the most important attribute, which is the similarity to the valuation subject. The proposed idea consequently necessitates the construction of an ever-new, different model of a selected part of the local market. Due to the selection made, the constructed market model achieves a relatively poor rating expressed by typical measures, such as variance or determination factor. In the nonneglected part of the experiments, however, it yields better price estimate results than those derived from a model built on unselected data. 
Based on the presented example of simulated data, it has been shown that, under conditions where there are comparative properties in the market data set that are similar to the valuation subject, basing the valuation on selected data allows the value of the valuation object to be determined with relatively better accuracy (smaller difference in estimation of $\widehat{\mathrm{Y}_{\mathrm{FB}}}$ in relation to the true value of $\mathrm{Y}_{\mathrm{T}}$ ). Unfortunately, this is not the rule. In the simulated experiment, some of the choices at the stage of looking for similar properties concerned transactions whose prices were extremely encumbered by unknown random errors. In such situations, the transaction price was sometimes uncorrelated with the quality assessments of the features of a given transaction object. Such a price (if included in the selected collection) causes a significant disturbance in the construction of the price model and, consequently, in the valuation of the subject property. Hence, there is a limited possibility of generalizing the request.

Nevertheless, the observations made allow the selection of sold properties (constituting the building blocks of the market database), made primarily due to the characteristics of the specific property adopted for the valuation, to be treated as a significant improvement in both the valuation practice of individual properties as well as an advancement in the constantly developing automated mass valuation algorithms.

The analyzed problem is important in the context of the question of whether valuers read the value based on researched market information or do they, in fact, create it. This issue was often raised in the context of the collapse of the real estate market in 2007-2009 in the USA. The return to the practice of valuation based primarily on the most similar real estate and not on the price model built on a broad spectrum of market data (also broad in the topographic sense) gives the chance to increase the credibility of valuation and gives ground to the thesis that the final result of the appraisal stems from research performed on the local market, and that the value is not created by the model itself.

Undeniably, the human factor is the weak link in the valuation system. As a result of the obvious limitations of man's ability to learn, human decisions are a source of subjectivity in valuation. However, automating the research process should not only mean maximizing the amount of information gathered, but should walk hand in hand with a diligent analysis of an unlimited spectrum of data. After the stage of data collection is completed, the valuation algorithm should be followed by a thought-through selection of recognized transactions and its leading criterion should not be the price but the characteristics of the valuation object. Considering this characteristic at the construction stage of the price model enables $g$ adequate accounting activities to be prepared as an element of real estate valuation and the result becomes an "assessed value" as opposed to the machine-based "estimation" which provides sums described as "appraisal value".

\section{Bibliography}

Albritton, H. (1982). Controversies in real property valuation: a commentary. American Institute of Real Estate Appraisers.

Anderson, R. E. (1960). The Comparison Approach in Appraising Residential Properties. The Appraisal Journal, (4), 178-181.

Arribas, I., García, F., Guijarro, F., Oliver, J., \& Tamošiuniene, R. (2016). Mass appraisal of residential realestate using multilevel modelling. International Journal of Strategic Property Management, 20(1), 77-87. https://doi.org/10.3846/1648715X.2015.1134702

Barańska, A. (2016). The Significance of Database Size in Modelling the Market of Nonresidential Premises. Real Estate Management and Valuation, 24(2), 47-56. https://doi.org/10.1515/remav-2016$\underline{0013}$

Bełej, M. (2013). Catastrophe theory in Explaining Price Dynamics on the Real Estate Market. Real Estate Management and Valuation, 21(3), 51-61. https://doi.org/10.2478/remav-2013-0026

Bitter, C., Mulligan, G. F., \& Dall'erba, S. (2007). Incorporating spatial variation in housing attribute prices: A comparison of geographically weighted regression and the spatial expansion method. Journal of Geographical Systems, 9(1), 7-27. https://doi.org/10.1007/s10109-006-0028-7

Bianco, K. M. 2008. The subprime lending crisis: Causes and effects of the mortgage meltdown. $\mathrm{CCH}$ Mortgage Compliance Guide and Bank Digest, New York, NY: CCH, Wolters Kluwer Law \& Business.

Bourassa, S. C., Cantoni, E., \& Hoesli, M. (2007). Spatial Dependence, Housing Submarkets, and House Price Prediction. The Journal of Real Estate Finance and Economics, 35, 143-160. https://doi.org/10.1007/s11146-007-9036-8 
Bourassa, S. C., Cantoni, E., \& Hoesli, M. (2010). Predicting House Prices with Spatial Dependence: A Comparison of Alternative Methods. JRER, 32(2), 139-159.

Bracke, P. (2015). House prices and rents: Micro evidence from a matched dataset in Central London. Real Estate Economics, 43(2), 403-431. https://doi.org/10.1111/1540-6229.12062

Brzezicka, J., \& Wiśniewski, R. (2012). Behawioralne aspekty rynku nieruchomości. Studia i Materiaty Towarzystwa Naukowego Nieruchomości, 20(2), 21-32.

Cellmer, R. (2014). The Possibilities and Limitations of Geostatistical Methods in Real Estate Market Analyses. Real Estate Management and Valuation, 22(3), 54-62. https://doi.org/10.2478/remav-2014$\underline{0027}$

Ciuna, M., Salvo, F., \& Simonotti, M. 2015. Appraisal Value and Assessed Value in Italy. International Journal of Economics and Statistics, 24-31, ISSN: 2309-0685.

Chun Lin, C. C., \& Mohan, S. B. (2011). Effectiveness comparison of the residential property mass appraisal-methodologies in the USA. International Journal of Housing Markets and Analysis, 4(3), 224243. https://doi.org/10.1108/17538271111153013

Ciuna, M., De Ruggiero, M., Salvo, F., \& Simonotti, M. (2017). Automated Procedures Based on Market Comparison Approach in Italy, in Advances in Automated valuation methodology. Springer International Publishing AG.

Colwell, P. F., Cannaday, R. E., \& Wu, C. (1983). The analytical foundations of adjustment grid methods. Journal of the American Real Estate and Urban Economics Association, 11(1), 11-29. https:// doi.org/10.1111/1540-6229.00277

d'Amato, M., \& Kauko, T. (2017). Advances in Automated valuation methodology. Springer International Publishing AG., https:// doi.org/10.1007/978-3-319-49746-4

Del Giudice, V., De Paola, P., \& Forte, F. (2017). Using Genetic Algorithms for Real Estate Appraisals. Buildings, 7(4), 31. Advance online publication. https:// doi.org/10.3390/buildings7020031

Diaz, J. (1990). The process of selecting comparable sales. The Appraisal Journal, 58(4), 533-540.

Dilmore, G. (1974). Appraising houses. Real Estate Appraiser, (July-August), 21-32.

Dmytrów, K., \& Gnat, S. (2019). Application of AHP Method in Assessment of the Influence of Attributes on Value in the Process of Real Estate Valuation. Real Estate Management and Valuation, 27(4), 15-26. https:// doi.org/10.2478/remav-2019-0032

Glumac, B., \& Des Rosiers, F. 2018. Real Estate And Land Property Automated Valuation Systems: A Taxonomy and Conceptual Model. SSRN Electronic Journal, https://doi.org/10.2139/ssrn.3183132

González, M. A. S., \& Formoso, C. T. (2006). Mass appraisal with genetic fuzzy rule-based systems. Property Management, 24(1), 20-30.

Janssen, C., Söderberg, B., \& Zhou, J. (2001). Robust estimation of hedonic models of price and income for investment property. Journal of Property Investment \& Finance, 19(4), 342-360. https://doi.org/10.1108/EUM0000000005789

Kontrimas, V., \& Verikas, A. (2011). The mass appraisal of the real estate by computational intelligence. Applied Soft Computing, 11(1), 443-448. Retrieved January 23, 2018, from https:/ /ac.elscdn.com https://doi.org/10.1016/j.asoc.2009.12.003

Kozioł-Kaczorek, D. (2012). Hierarchizacja cech nieruchomości z zastosowaniem Analitycznego Procesu Hierarchicznego. Studia i Materiały Towarzystwa Naukowego Nieruchomości, 20(1), 165-174.

Lughofer, E., Trawiński, B., Trawiński, K., Kempa, O., \& Lasota, T. (2011). On employing fuzzy modelling algorithms for the valuation of residential premises. Information Sciences, 181(23), 51235142. https://doi.org/10.1016/j.ins.2011.07.012

McCluskey W.J. Borst R.A., 2017, The Theory and Practice of Comparable Selection in Real Estate Valuation d'Amato M. and Kauko T. ed. Advances in Automated valuation methodology, Studies in Systems, Decision and Control, Springer International Publishing, pp. 307-330, DOI https://doi.org/10.1007/978-3-319-49746-4.

Mimis, A., Rovolis, A., \& Stamou, M. (2013). Property valuation with artificial neural network: The case ofAthens. Journal of Property Research, 30(2), 128-143. https://doi.org/10.1080/09599916.2012.755558

Moore, J. W. (2009). A History of Appraisal Theory and Practice Looking Back from IAAO's 75th Year. Journal of Property Tax Assessment \& Administration, 6, 23-49. 
Pagourtzi, E., Assimakopoulos, V., Hatzichristos, T., \& French, N. (2003). Real estate appraisal: A review of valuation methods. Journal of Property Investment \& Finance, 21(4), 383-401. https://doi.org/10.1108/14635780310483656

Peto, R., French, N., \& Bowman, G. (1996). Price and worth: Developments in valuation methodology. Journal of Property Valuation and Investment, 14(4), 79-100. https://doi.org/10.1108/14635789610153489

Shenkel, W. M., \& Eidson, A. S. (1971). Comparable sales retrieval systems. The Appraisal Journal, October, $540-555$.

Shiller, R. (1990). Speculative prices and popular models. The Journal of Economic Perspectives, 4, 55-65. https://doi.org/10.1257/jep.4.2.55

Simonotti, M., Salvo, F., \& Ciuna, M. (2014). Multilevel Methodology Approach for the Construction of Real Estate Monthly Index Numbers. Journal of Real Estate Literature, 22(2), 281-302.

Tchira, A. (1979). Comparable sales selection -A computer approach. The Appraisal Journal, 47(1):86-98.

Trojanek, M. (2010). Methodic of estate valuation in Poland-actual status. Economia e Sociologia, 3(1), 66-75. https://doi.org/10.14254/2071-789X.2010/3-1/7

Żelazowski, A. (2008). Zjawisko baniek cenowych na rynkach nieruchomości. Studia i Materiaty Towarzystwa Naukowego Nieruchomości, 16(4), 99-108.

Zyga, J. (2019). Dissimilarity as a Component of the Property Price Model. Real Estate Management and Valuation, 27(3), 124-132. https:// doi.org/10.2478/remav-2019-0030

Zyga J. 2020. The influence analysis of criteria of comparables selection on the accuracy of the property value estimation. Reports on Geodesy and Geoinformatics, not published. accepted 202003-26. International Valuation Standards Council (IVSC), (2010). Exposure Draft of New International Valuation Standards. London: IVSC

Royal Institution of Chartered Surveyors (RICS). (2017). RICS Valuation - Global Standards 2017. London: RICS. http://www.rics.org/pl/knowledge/professional-guidance/redbook/ricsvaluation-global-standards-2017/

Standard's Commision of Polish Federation of Valuer's Associations (SCPFVA) (2009).

US Appraisal Standard Board (USPAP). (2017). http://www.uspap.org 